\title{
Posterior corneal dystrophy
}

INSERM

\section{Source}

INSERM. (1999). Orphanet: an online rare disease and orphan drug data base. Posterior corneal dystrophy. ORPHA:98627

Posterior corneal dystrophies refers to a group of rare genetically determined corneal dystrophies (CDs) characterized by lesions affecting the corneal endothelium and Descemet membrane, and variable effects on vision depending on the type of dystrophy. 